\title{
Article
}

\section{Analysis of Organizational Factors Affecting Employee Innovation}

\author{
Sania Khan* \\ Assistant Professor \\ College of Business Administration, Prince Sattam Bin Abdulaziz University, Al Kharj, K.S.A \\ *Correspondence: saniakhan05@gmail.com; sa.khan@psau.edu.sa
}

\begin{abstract}
Organizations with proper human resources (HR) practices play an exemplary role in developing their employees' innovation. Though there is extensive literature on managing organizational innovation, even in today's scenario some organizations stand as a barrier for employees' growth and innovation at the workplace. This study aimed to holistically explore the organizational factors affecting employee innovation using principal component analysis (PCA) and condense the dimensionalities for a better focus of organizational development. The study executed a survey questionnaire and collected useful data from one hundred and ninety-five (195) respondents of various Indian companies. The study identified forty-six sub-factors and evolved into nine major organizational factors influencing employee innovation namely organization structure, organization culture and environment, corporate strategy, innovation process, employee, technology, resources, knowledge management and management and leadership. The study recommended that any firm must focus on these factors to encourage employee innovation leading to overall organizational success. It also provides broad implications to HR managers, firm policymakers and top management to reassess and formulate the best organizational strategies to promote innovation culture in the organization.
\end{abstract}

Keywords: Organizational factors, employee creativity, employee innovation, workplace innovation, principal component analysis.

\section{Introduction}

Previous research studies in HR management extensively stressed on employee innovation susceptibility, employee and operational competencies, managing organizational innovation and their related aspects, theories and models of work-life, socio-cultural issues as key determinants for organization success. On the other side, exploring the holistic view of organizational factors concerning employee innovation was confined which needs more attention in the emerging scientific arena of HR. Innovation has a very broad sense. But in this study, we refer to employee innovation. In many past studies, employee creativity and innovativeness were used interchangeably. The main difference is creativity denotes the idea generation and innovation as an application of those ideas in advancement with the process of assessment and implementation. Hence creative behavior is a prerequisite for innovation. For the research purpose, we consider [37] definition of creativity as the generation of a novel idea in a particular field. On the other side, [26] defined innovation as a series of processes right from problem identification, creating new ideas, evaluation, and implementing them.

Many researchers stressed that the organization must flourish in innovation to endure heavy competition $[30,22,29]$. Though there exists some systematic literature from an organization perspective like $[25,2]$ lacked to explain the statistical dimensionalities of various identified factors. While few studies missed 
addressing organizational factors from an employee perspective; and other studies failed to consider a holistic view. Therefore, there exists a research gap from an organizational viewpoint to emphasize developments from various aspects and on the most important ones. Therefore, this study attempted to identify organizational factors holistically and statically reduce the dimensionalities supporting the organizations.

Despite understanding the role of the organization in stimulating the innovation process, empirical studies on factors affecting employee innovation were very limited in India and also scattered. Considering the organizational factors as interrelated to each other, we recommend considering innovation in a holistic view also by including few contingent factors. Therefore, this study aimed to bridge the gap by exploring the possible number of organizational dimensions using the PCA method. The study is organized into six sections. Firstly, it presents the background of the topic. Secondly, it provides a retrospective literature review. The next research method and data analysis were presented followed by a conclusion and managerial implications, further research direction, and limitations of the study.

\section{Literature Review}

[1] explored five factors namely organizational culture, organizational climate, leadership style, skills and resources, and organization structure and system will encourage employee creativity. Similarly, [9] explained twenty-one components improve creativity and innovation but to list the most important are as challenges in job, teamwork, job rotation, autonomy in the job, supervisor coaching, time for thinking, creative objectives, recognition of creative ideas, incentives. [17] explored that employee creativity and organizational innovation are greatly influenced by good HR practices. Those components in HR practices positively affecting employee creativity are hiring and selection process, rewards, job design and teamwork but not training and performance appraisal. [2] identified twelve factors for an effective organizational innovation namely; management support, customer focus, internal and external communication, HR strategies, teamwork, leadership, knowledge management, creative development, strategic posture, flexible structures, constant improvement, technology implementation. The author states these twelve factors cover the macro level of an organization and management support found to be the most important determinant as it plays a vital role in inculcating innovative culture, implement new structures and processes and embrace innovation as a strategic perquisite. [31] conducted research study to understand the relationship between various individual and organizational factors and their effect on knowledge sharing behavior. Some of the variables used in the study were management support, leadership, organization's incentives and reward system, organizational culture and found these dimensions have high significant relation with knowledge sharing and also mediate such behavior in organization.

[25] systematic and structured literature review on 102 research papers and identified 31 sub-factors and derived into nine generic factors for managing organizational innovation and developed a conceptual model. The authors have taken care to eliminate irrelevant, iterating factors and even which falls under common themes with different headings. Therefore, this study considered major factors from [25] to gather a possible number of relevant factors. However, their study lacks an empirical evaluation of the identified factors and failed to consider contingency factors. Another study by [10] considered fourteen contingency factors to study the relationship between structural complexity and organization size with organizational innovation. The findings showed structural complexity depends on the complexity of operations, environmental uncertainty, use of service and manufacturing firms, focus on technical, product and implementation of innovations. Whereas organization size is dependent on operational size, environmental uncertainty, service and profits of organization, technical and product emphasize innovations. Another recent study by [21], considered essential organizational factors of Saudi firms which affect the employees. 
Those organizational factors are reflective of employees' responses. Hence some of these factors were considered as sub-factors under main headings in this study. However, this study conducted exploratory factor analysis (EFA), but could not cover consider holistic dimensions. The findings demonstrated training and brainstorming sessions; employee recognition and rewards; resources and fund allocation; employee competencies; work environment and management support have a significant effect on employee innovation. [21] also stressed that management support is predominant for organization success only if it supports providing proper training on technology and work-related, mobilizes the workforce, implements appropriate business models, and formulate new policies and strategies. Unfortunately, the least coefficient value explained organizations give the least preference to support their employees' innovation due to the prevailing dominating culture of individuals in higher job positions. $[4,5,20]$ emphasized HR strategies and found the HR department has a significant role in spreading information and relevant knowledge about innovation. Further, [34] adds technological innovation is vital for manufacturing and service industries, for which the employees need to be trained on new technologies.

Management support is a great influencer in boosting the employees' innovative behavior by stimulating the spawn of creative ideas and applying them in daily work life [4,5,35,36,38,15]. [8,5,36] study on managers' leadership behavior revealed that they are accountable to establish pioneering strategies reinforces employees' innovation. Similarly, another study by [32] used the ambidexterity theory of leadership to understand the inconsistent relation between leadership and innovation receptiveness of employees. Two sets of leadership behaviors were used and named it as mirrors symmetry leadership as the leaders can toggle between opening and closing behaviors. It was found the development of rich ties among employees during the formal and informal interactions transferred the knowledge and innovative behavior among the peer even when the power of the team was controlled. [7] study addressed the relation between employee innovative susceptibility and unfavorable working conditions. It explained more workload assigned by leaders may adverse employee innovation. Therefore, leaders must act very sensitively in developing relational conduits to solve employee stress related to work. The identified factors from the literature were also presented in below Table 1.

Table 1. Factors and sub-factors identified from the literature review

\begin{tabular}{|c|c|c|c|c|c|}
\hline S. No & Factor & Sub-Factors & $\begin{array}{c}\text { S. } \\
\text { No }\end{array}$ & Factor & Sub-Factors \\
\hline 1 & $\begin{array}{l}\text { Organizational } \\
\text { Structure }\end{array}$ & $\begin{array}{ll}\text { - } & \text { Organizational } \\
& \text { differentiation (QS1) } \\
\text { - } & \text { Centralization (QS2) } \\
\text { - } & \text { Formality (QS3) } \\
\text { - } & \text { Size of an organization } \\
& (\mathrm{QS4})\end{array}$ & 6 & Technology & $\begin{array}{l}\text { - Technology utilization } \\
\text { T1) } \\
\text { - Technical skills and } \\
\text { education (T2) } \\
\text { - Deployment of new } \\
\text { technology (T3) }\end{array}$ \\
\hline
\end{tabular}




\begin{tabular}{|c|c|c|c|c|c|}
\hline 2 & $\begin{array}{c}\text { Organizational } \\
\text { Culture and } \\
\text { Environment }\end{array}$ & $\begin{array}{ll}\text { - Open Communication } \\
\text { (QCE1) } \\
\text { - Collaboration (QCE2) } \\
\text { - Risk and environment } \\
\text { uncertainty (QCE3) } \\
\text { - Attitude to innovation } \\
\text { (QCE4) } \\
\text { - Autonomy (QCE5) } \\
\text { - Dynamic work culture } \\
\text { (QCE6) } \\
\text { - Team Spirit (QCE7) }\end{array}$ & 7 & Resources & $\begin{array}{l}\text { - } \text { Mobilize talent (R1) } \\
\text { - } \text { Simplify \& } \\
\text { streamlining business } \\
\text { process (R2) } \\
\text { - Utilization of slack } \\
\text { resources (R2) } \\
\text { - Planning and } \\
\text { management of } \\
\text { resource (R4) } \\
\text { - Knowledge resources } \\
\text { (R5) } \\
\text { - Technology resources } \\
\text { (R6) } \\
\text { - Financial resources } \\
\text { (R7) }\end{array}$ \\
\hline 3 & $\begin{array}{l}\text { Corporate } \\
\text { Strategy }\end{array}$ & $\begin{array}{l}\text { - Organizational Strategy } \\
\text { (CS1) } \\
\text { - Innovation Strategy } \\
\text { (CS2) } \\
\text { - Vision and Mission } \\
\text { (CS3) }\end{array}$ & 8 & $\begin{array}{l}\text { Knowledge } \\
\text { Management }\end{array}$ & $\begin{array}{ll}\text { - } & \text { Knowledge sharing } \\
& \text { (KM1) } \\
\text { - } & \text { Organizational } \\
& \text { learning (KM2) } \\
\text { - } & \text { Knowledge of internal } \\
\text { and external } \\
\text { environment (KM3) } \\
\text { - Utilization of } \\
\text { knowledge } \\
\text { repositories (KM4) }\end{array}$ \\
\hline 4 & $\begin{array}{l}\text { Innovation } \\
\text { Process }\end{array}$ & $\begin{array}{l}\text { - Idea generation (IP1) } \\
\text { - Selection and evaluation } \\
\text { techniques (IP2) } \\
\text { - Implementation } \\
\text { Mechanism (IP3) } \\
\text { - Stage in innovation } \\
\text { adoption (IP4) }\end{array}$ & 9 & $\begin{array}{c}\text { Management } \\
\text { and } \\
\text { Leadership }\end{array}$ & $\begin{array}{l}\text { - } \text { Employee } \\
\text { empowerment and } \\
\text { trust (ML1) } \\
\text { - Business opportunity } \\
\text { (ML2) } \\
\text { - Deploy diversified } \\
\text { talents (ML3) } \\
\text { - Good HR practices } \\
\text { (ML4) } \\
\text { - Management } \\
\text { Personalities (ML5) } \\
\text { - Management Style } \\
\text { (ML6) }\end{array}$ \\
\hline 5 & Employee & $\begin{array}{l}\text { - } \text { Competencies (E1) } \\
\text { - Self-development plans } \\
\text { (E2) } \\
\text { - Think out of the box } \\
\text { (E3) } \\
\text { - Motivation to learn (E4) } \\
\text { - Employee personalities } \\
\text { (E5) }\end{array}$ & & & \\
\hline
\end{tabular}




\begin{tabular}{|c|c|c|}
\hline & & $\begin{array}{l}\text { - Training and } \\
\text { brainstorming (E6) } \\
\text { - Performance appraisal } \\
\text { (E7) } \\
\text { - Recognition and } \\
\text { Reward (E8) }\end{array}$ \\
\hline
\end{tabular}

Source: Factors identified from literature review

\section{Methodology}

The study followed a systematic research process in four-folds. Firstly, it identifies factors and sub-factors from the relevant literature, then designing the questionnaire and data collection lastly followed by data analysis. Based on the identified factors from literature a well-designed questionnaire was developed on a 5-point Likert scale. The study adopted a quantitative research method by using closed-ended questions to collect appropriate information from two hundred and fifteen (215) respondents from various Indian companies which were administered among managerial levels who involve in organizational and employee development. However, the useful data resulted in one hundred and ninety-five (195) respondents only. SPSS (software package for social services) version 23 was used to analyze the data. Table 1 shows the coding of all the sub-factors of an organization towards employee innovation.

\section{Data analysis and results discussion}

The demographic data of the respondents namely age, academic qualification, job position and experience were tabulated in Table 2.

\section{Respondents Demographic Data}

As shown in Table 2, the age group of respondents is from 21 to 60 years and the majority of them fall under the age group of $31-40$ years (34.8\%) between 6 to 10 years (31.2\%) of job experience. The majority of them hold master's degrees $112(57.4 \%)$ and $126(66.1 \%)$ of them working in top level managerial positions with most of them $92(47.1 \%)$ belonging to medium size organization. The least $22(11.2 \%)$ are within the age group of $21-30$ years and very few 31 (15.8\%), have a doctorate. While the least are from the big organization with $27(13.8 \%)$ and middle-level respondents are $69(35.3 \%)$ and $34(17.4 \%)$ have 5 years and less experience.

Table 2. Demographic data of respondents

\begin{tabular}{cccc}
\hline Variable & Category & Frequency & \% \\
\hline \multirow{2}{*}{ Age } & $21-30$ years & 22 & 11.2 \\
& $31-40$ years & 68 & 34.8 \\
& $41-50$ years & 56 & 28.7 \\
& $51-60$ years & 49 & 25.1 \\
\hline \multirow{2}{*}{ Education } & Bachelors & 52 & 26.7 \\
& Masters & 112 & 57.4
\end{tabular}




\begin{tabular}{|c|c|c|c|}
\hline & Doctorate & 31 & 15.8 \\
\hline \multirow{3}{*}{$\begin{array}{c}\text { Organization } \\
\text { Size }\end{array}$} & $<500$ employees & 76 & 38.9 \\
\hline & $>500$ but $<1000$ & 92 & 47.1 \\
\hline & $>1000$ & 27 & 13.8 \\
\hline \multirow{2}{*}{ Designation } & Top Level & 126 & 66.1 \\
\hline & Middle Level & 69 & 35.3 \\
\hline \multirow{4}{*}{ Experience } & $1-5$ years & 34 & 17.4 \\
\hline & $6-10$ years & 61 & 31.2 \\
\hline & 11 - 15 years & 53 & 27.1 \\
\hline & 16 and above & 47 & 24.1 \\
\hline
\end{tabular}

Source: Primary data analysis

\section{Principal Component Analysis of Organizational Factors}

All the items were developed to find the relevance of measurement scale to their respective construct, the exploratory factor analysis was conducted in this study to establish organizational factors (constructs) reliability and validity. To examine the factorability condition, a measure of sampling adequacy is used by checking the Kaiser-Meyer-Olkin (KMO) value and Bartlett's test of sphericity of organizational factors data. As recommended by [18] the KMO value below 0.5 does not do factor analysis. While Bartlett's test of sphericity tests the hypothesis that the correlation matrix is an identity matrix. Values of 0.05 or less must be good and essentially significant at $\mathrm{p}<0.001$. In this study, the KMO is 0.857 and Bartlett's test value was significant at $\mathrm{p}=0.000$ demonstrating a fair factorability condition as shown in Table 3.

Table 3. KMO and Bartlett's test of sphericity of organizational factors

\begin{tabular}{lrr}
\hline Method & \multicolumn{1}{c}{ Value } \\
\hline Kaiser-Meyer-Olkin measure of sampling adequacy & & 0.857 \\
& & \\
Bartlett's test of sphericity & Approx. Chi-square & 1864.54 \\
& df & 482 \\
& sig. & 0.000 \\
\hline
\end{tabular}

Source: Primary data analysis

Table 4 explains the summary of the rotated factor matrix of organizational factors using Principal Component Analysis with Varimax rotation under Kaiser Normalization [19]. The PCA method and rotation converged into 8 iterations. All the forty-six sub-factors were extracted into nine factors and accounted for $74.83 \%$ of the total variance. Only those factor loading above 0.50 were considered to be significant [14]. 


\section{Factor 1. Organization Structure}

This component constitutes of four items and accounted for $4.43 \%$ of the variance. This shows the organization structure differentiates (0.943) from other organizations, which need to be centralized (0.923) and formal (0.911) and the size also defines the organizational structure and its innovation process (0.894). The results also validate the findings of Marisa Smith et al., 2008 and Lewis and Moultrie, 2005 stating the structure of a firm is conducive to actual innovation management and also directs the job nature to its employees.

\section{Factor 2. Organizational Culture and Environment}

This component constitutes of four items and accounted for the $18.72 \%$ of variance. This shows the culture and environment will affect the employees learning through open communication (0.874) being collaborative (0.889) among their peers. There may be some kind of risk factor (0.878) in the environment while trying new methods at work. However, the innovational attitude (0.904) is vital to attain organizational success. Other factors like autonomy (0.854), dynamic work culture (0.886) and team spirit (0.871) may empower the employees with good command and control on their work. This finding is also consistent with many past studies, which mentioned the organization culture is predominant and opens new methods in dealing with various tasks. Further risk-taking, open communication, innovative attitude privileges the generation of new ideas, and flow of work-related information to the employees $[12,25]$. The findings of this study were also aligned with findings of [31] about organization culture on knowledge sharing among employees.

\section{Factor 3. Corporate Strategy}

This component constitutes of four items and accounted for $5.15 \%$ of the variance. This shows organizational strategy $(0.947)$ can slowly drive the culture and formalize the innovation strategy (0.951) and propagates the firms' vision and mission $(0.954)$. This finding is consistent with $[16,6]$ whose study stated the corporate strategy reflects the firm's culture and disseminates a common vision and objectives of the organization and institutionalizes for the employees.

\section{Factor 4. Innovation Process}

This component constitutes of four items and accounted for $11.84 \%$ of the variance. The innovation process follows step by step process where employee idea generation (0.911) is the first stage which is further supported by management in the selection and evaluation of techniques $(0.865)$ and then identifying the implementation mechanism (0.895) which will finally result in the various stages of innovation adoption (0.923). These factors were identified by [25] and validated in this study, which is further supported by many studies [24,3]. [13] also affirmed that idea generation and adoption of innovation will provide various solutions between the process and product development; incremental versus radical; and administrative versus technical aspects.

\section{Factor 5. Employee}

This component constitutes of four items and accounted for $20.42 \%$ of the variance. Employees act as a channel between organizational factors and the innovation process as they were found as a potential source to reinforce innovation. Therefore, employee competencies (0.865) help them in self-development plans (0.869) which allows them to think out of the box (0.888). Further, the organization must motivate them to learn $(0.843)$ by providing necessary training and brainstorming $(0.946)$. Also better performing employee 
personalities (0.867) must be recognized and rewarded (0.849) through a proper performance appraisal system $(0.876)$. These factors were previously undertaken by many past studies [28,33]. This finding is also supported by [21] who confirmed that training and brainstorming, the ability of an employee to think out of the box, employee competencies and recognition and reward for innovative employees have a positive correlation with innovation.

\section{Factor 6. Technology}

This component constitutes of four items and accounted for $2.34 \%$ of the variance. Technology utilization (0.799) can expedite the work process and employee performance provided employees to possess technical skills and education (0.804) at work. Therefore, the organization must deploy new technology (0.821) to manage the innovation process. This statement is also supported by $[24,27]$ who affirmed that the use of technology at work helps in generating new ideas improving the various stages of the innovation process.

\section{Factor 7. Resources}

This component constitutes of four items and accounted for $9.54 \%$ of the variance. Resources include all the inputs of an organization such as manpower, knowledge, finance, technology, and so on. The study identified such relevant resources and argues mobilizing talents (0.908) is vital to make availability of skilled labor at all levels and create opportunities for individuals to grow. In this, the knowledge resources (0.855) technology resources (0.932) have a significant role and helps in fast developments. Therefore, the management must focus on the best utilization of slack resources (0.899), do proper planning and management of resources (0.831), and provide financial resources (0.911) along with simplifying and streamlining business processes (0.981). These findings were also consistent with various studies $[21,24,27]$.

\section{Factor 8. Knowledge Management}

This component constitutes of four items and accounted for $1.12 \%$ of the variance. Employees' innovation comes from organizational learning (0.792) which in turn comes from gaining knowledge from the internal and external environment (0.902). [21] found the employees who learn from their peers through knowledge sharing $(0.875)$ and utilizing the knowledge repositories (0.816) that are available in the organization will flourish soon. The findings of this study were also consistent with findings of [31] that knowledge sharing among employees will improve the knowledge management in an organization.

\section{Factor 9. Management and Leadership}

This component constitutes of four items and accounted for $1.24 \%$ of the variance. [11] mentioned the innovative output and growth of an organization are powered by the knowledge management of a firm and will empower their employees' trust (0.922). Therefore, the management must deploy diversified talents (0.898) with good HR practices (0.894) creating new business opportunities (0.942), but it is possible by possessing good management personalities (0.915) and a management style (0.946). The findings of this study were also consistent with findings of [31] that there must be strong support from management and leadership to promote knowledge sharing among employees which will in turn help in overall success of organization. 
Tale 4. Rotated Factor Matrix

\begin{tabular}{|c|c|c|c|c|c|c|c|c|c|}
\hline \multirow[t]{2}{*}{ Item } & \multicolumn{9}{|c|}{ Components } \\
\hline & 1 & 2 & 3 & 4 & 5 & 6 & 7 & 8 & 9 \\
\hline OS1 & & & & & & 0.943 & & & \\
\hline OS2 & & & & & & 0.923 & & & \\
\hline OS3 & & & & & & 0.911 & & & \\
\hline OS4 & & & & & & 0.894 & & & \\
\hline OCE1 & & 0.874 & & & & & & & \\
\hline OCE2 & & 0.889 & & & & & & & \\
\hline OCE3 & & 0.878 & & & & & & & \\
\hline OCE4 & & 0.904 & & & & & & & \\
\hline OCE 5 & & 0.854 & & & & & & & \\
\hline OCE 6 & & 0.886 & & & & & & & \\
\hline OCE 7 & & 0.871 & & & & & & & \\
\hline CS1 & & & & & 0.947 & & & & \\
\hline CS2 & & & & & 0.951 & & & & \\
\hline CS3 & & & & & 0.954 & & & & \\
\hline IP1 & & & 0.911 & & & & & & \\
\hline IP2 & & & 0.865 & & & & & & \\
\hline IP3 & & & 0.895 & & & & & & \\
\hline IP4 & & & 0.923 & & & & & & \\
\hline E1 & 0.865 & & & & & & & & \\
\hline E2 & 0.869 & & & & & & & & \\
\hline E3 & 0.888 & & & & & & & & \\
\hline E4 & 0.843 & & & & & & & & \\
\hline E5 & 0.867 & & & & & & & & \\
\hline E6 & 0.946 & & & & & & & & \\
\hline E7 & 0.876 & & & & & & & & \\
\hline E8 & 0.849 & & & & & & & & \\
\hline T1 & & & & & & & 0.799 & & \\
\hline $\mathrm{T} 2$ & & & & & & & 0.804 & & \\
\hline T3 & & & & & & & 0.821 & & \\
\hline R1 & & & & 0.908 & & & & & \\
\hline $\mathbf{R} 2$ & & & & 0.981 & & & & & \\
\hline R3 & & & & 0.899 & & & & & \\
\hline R4 & & & & 0.831 & & & & & \\
\hline R5 & & & & 0.855 & & & & & \\
\hline R6 & & & & 0.932 & & & & & \\
\hline R7 & & & & 0.911 & & & & & \\
\hline KM1 & & & & & & & & & 0.875 \\
\hline KM2 & & & & & & & & & 0.792 \\
\hline KM3 & & & & & & & & & 0.902 \\
\hline KM4 & & & & & & & & & 0.816 \\
\hline
\end{tabular}




\begin{tabular}{|c|c|c|c|c|c|c|c|c|c|}
\hline ML1 & & & & & & & & 0.922 & \\
\hline ML2 & & & & & & & & 0.942 & \\
\hline ML3 & & & & & & & & 0.898 & \\
\hline ML4 & & & & & & & & 0.894 & \\
\hline ML5 & & & & & & & & 0.915 & \\
\hline ML6 & & & & & & & & 0.946 & \\
\hline $\begin{array}{l}\text { Initial Eigen } \\
\text { Value }\end{array}$ & 3.302 & 2.824 & 2.481 & 2.246 & 1.952 & 1.847 & 1.458 & 1.381 & 1.231 \\
\hline$\%$ Variance & 20.428 & 18.724 & 11.842 & 9.542 & 5.151 & 4.438 & 2.346 & 1.241 & 1.125 \\
\hline Cumulative \% & 20.428 & 39.152 & 50.994 & 60.536 & 65.687 & 70.125 & 72.471 & 73.712 & 74.837 \\
\hline
\end{tabular}

\section{Limitations and Scope of Further Research}

Though this study does not demonstrate methods to develop on organizational innovation, it helps to focus on various organizational factors using statistically reduced dimensionalities. The study focused on general holistic organizational factors but may lack to consider specific industries. Also as employees are key stakeholders of an organization, the qualitative responses of employees' were not considered. Any further research studies may consider a qualitative approach in gathering employees' viewpoints using thematic analysis, Delphi study, or focused group to list more appropriate organizational factors specific to industrywise.

\section{Conclusion and Managerial Implications}

The organizational factors affect employee innovation and also in the long run will determine the organization's success. The findings of this paper contribute to a better understanding of the various organizational factors holistically. Not only the study identified and validated the determinants, but it also contributes both in the theoretical explanations of the organizational factors and categorization of huge factors into reduced dimensionalities. The study reduced the dimensions into nine (9) Important organizational factors, 1) Organizational Structure 2) Organizational Culture and Environment 3) Corporate Strategy 4) Innovation Process 5) Employees 6) Technology 7) Resources 8) Knowledge Management 9) Management and Leadership. This method of factor reduction will assist the organization development authorities and the innovation managers to focus on various aspects easily. These dimensions are almost common for any industry and therefore the managers must efficiently focus on them irrespective of any type of industry. Sometimes the work and organization culture differs among the firms of a different continent. Therefore, further researchers may conduct similar studies in different nations and continents using these factors with more sample size and compare the results for further growth and development of the organizations.

Funding: The author(s) received no financial support for the research, authorship, and/or publication of this article.

Conflicts of Interest: The authors declare no conflicts of interest.

\section{References}

1. Andriopoulos, C. Determinants of organizational creativity: a literature review. Manag. Decis. 2001, 39(10), 834841. 10.1108/00251740110402328 
2. Anthony R. Determinants of successful organizational innovation: A review of current research. J. Manag. Prac. 2000, 3(1), 95-119. $\quad$ https://www.semanticscholar.org/paper/DETERMINANTS-OF-SUCCESSFULORGANISATIONAL-\%3A-A-OF-Read/24e2c196230108e57724b6372ec96ae2c76c030f

3. Aranda, D. A.; Molina, L. M. Determinants of innovation through a knowledge-based theory lens. Industrl Manag. Data Sys. 2002, 102, 289-298. https://doi.org/10.1108/02635570210428320

4. Atuahene-Gima, K. Differential Potency of Factors Affecting Innovation Performance in Manufacturing and Services Firms in Australia. J. Product. Innov. Manag. 1996, 13(1), 35-52. https://doi.org/10.1016/0737$\underline{6782(95) 00090-9}$

5. Balbontin, A.; Yazdani, B.; Cooper, R.; Souder, W. E. New Product Success Factors in American and British firms. Intl. J. Techno. Manag. 1999, 17(3), 259-80. https://doi.org/10.1504/IJTM.1999.002715

6. Cottam, A.; Ensor, J.; Band, C. A. Benchmark study of strategic commitment to innovation. Eur. J. Innov. Manag. 2001, 4(2), 88-94. https://doi.org/10.1108/14601060110390594

7. De Clercq D.; Dimov D.; Belausteguigoitia I. Perceptions of Adverse Work Conditions and Innovative Behavior: The Buffering Roles of Relational Resources. Entrepre. Theory and Prac. 2016, 40(3), 515-542 https://doi.org/10.1111/etap.12121

8. De Jong J.P.J.; Den Hartog D.N. How leaders influence employees' innovative behavior. Eur. J. Innov. Manag. 2007, 10 (1), 41-64. https://hdl.handle.net/11245/1.529560

9. Dul, J.; Ceylan, C. Work environments for employee creativity. Ergonomics 2011, 54(1), 12-20.

DOI: $10.1080 / 00140139.2010 .542833$

10. Fariborz D. Organizational Complexity and Innovation: Developing and Testing Multiple Contingency Models. Manag. Sci. 1996, 42(5), 693-716. https://doi.org/10.1287/mnsc.42.5.693

11. Fiol, C. M. Squeezing Harder Doesn't Always Work: Continuing the Search for Consistency in Innovation Research. Academy Manag. Rev. 1996, 21(4), 1012-21. https://doi.org/10.5465/amr.1996.15868543

12. Giambatista, Robert C.; Bhappu, Anita D. Diversity's harvest: Interactions of diversity sources and communication technology on creative group performance. Organ. Behav. Hum. Decis. Process 2010, 111(2), 116126. https://doi.org/10.1016/j.obhdp.2009.11.003

13. Gopalakrishnan, S.; Damanpour, F. A Review of Innovation Research in Economics. Sociology and Technology Management. Omega, Intl. J. Manag. Sci. 1997, 25(1),15-28. https://doi.org/10.1016/S0305-0483(96)00043-6

14. Hair, J.F., Black, W.C., Babin, B.J., Anderson, R.E. Tatham, R.L. Multivariate Data Analysis, 2006, 6, Pearson Prentice Hall, Upper Saddle River. https://www.scirp.org/(S(lz5mqp453edsnp55rrgjct55))/reference/ReferencesPapers.aspx?ReferenceID=1747215

15. Hurley, R. F.; Hult, G. T. Innovation, Market Orientation, and Organizational Learning: An Integration and Empirical Examination. J. Marketing 1998, 62(3), 42-54. https://doi.org/10.1177/002224299806200303

16. Jager, B.; Minnie, C.; Jager, J.; Welgemoed, M. Enabling continuous improvement: A case study of implementation. J. Manuf. Techno. Manag. 2004, 15(4), 315-331. https://doi.org/10.1108/17410380410535017

17. Jiang, J.; Wang, S.; Zhao, S. Does HRM facilitate employee creativity and organisational innovation? A study of Chinese firms. The Intl J. Hum. Reso. Manag. 2012, 23(19), 4025-4047.

https://doi.org/10.1080/09585192.2012.690567

18. Kaiser, H. A second generation little jiffy. Psychometrika 1970, 35(4), 401-415. https://doi.org/10.1007/BF02291817

19. Kaiser, H. F. The Varimax Criterion for Analytic Rotation in Factor Analysis. Psychometrika 1958, 23(3), 187-200. https://doi.org/10.1007/BF02289233

20. Keogh, W. Understanding Processes and Adding Value Within Innovative Small Firms. Knowledge and Process Manag. 1999, 6(2), 114-25. https://doi.org/10.1002/(SICI)1099-1441(199906)6:2<114::AID-KPM56>3.0.CO;2-A

21. Khan S.; Mohiya M. Determinants of SMEs employees' creativity and their impact on innovation at workplace. Manag. Sci. Letters 2020, 10(16), 3865-3872. 10.5267/j.msl.2020.7.025

22. Lengnick-Hall, C. A. Innovation and competitive advantage: What we know and what. J. Manag. 1992, 18(2), 399-429. https://doi.org/10.1177/014920639201800209

23. Lewis, M.; Moultrie, J. The organizational innovation laboratory. Creativity and Innov. Manag. 2005, 14(1), 7386. https://doi.org/10.1111/j.1467-8691.2005.00327.x

24. Loewe, P.; Dominiquini, J. Overcoming the barriers to effective innovation. Strategy and Leadership 2006, 34(1), 24-31. https://doi.org/10.1108/10878570610637858 
25. Marisa S.; Marco B.; Peter B.; Robert Vander M. Factors Influencing an Organizations ability to Manage Innovation: A Structured Literature Review and Conceptual Model. Intl J. Innov. Manag. 2008, 12 (4), 655-676. https://doi.org/10.1142/S1363919608002138

26. Mumford, M. D.; Scott, G. M.; Gaddis, B.; Strange, J. M. Leading creative people. Orchestrating expertise and relationships Leadership Quart. 2002, 13, 705- 750.

27. Pissarra, J., Jesuino, J. C. Idea generation through computer-mediated communication: The effects of anonymity. J. Managerial Psychol. 2005, 20, 275-291. https://doi.org/10.1108/02683940510589055

28. Pohlmann, M.; Gebhardt, C.; Etzkowitz, H. The development of innovation systems and the art of innovation management - strategy, 21 control and the culture of innovation. Techno. Analy. Strategic Manag. 2005,7(1), 1-12. https://doi.org/10.1080/09537320500044206

29. Porter, M. E. The competitive advantages of nation, 1990, London, UK: Macmillian Press. http://www.economie.ens.fr/IMG/pdf/porter 1990 - the competitive advantage of nations.pdf

30. Roberts, R. Managing innovation: The pursuit of competitive advantage and the design of innovation intense environments. Research Policy 1998, 27, 159-175. https://doi.org/10.1016/S0048-7333(98)00034-1

31. Rohman, A.; Anis Eliyana, A.; Purwana, D.; Hamidah. Individual and organizational factors' effect on knowledge sharing behavior. Entrepreneurship and Sustainability Issu. 2020, 8(1), 38-48. http://doi.org/10.9770/jesi.2020.8.1(3)

32. Rosing K.; Frese M.; Bausch A. Explaining the heterogeneity of the leadership-innovation relationship: Ambidextrous leadership. Leadership Quart. 2011, 22(5), 956-974. https://doi.org/10.1016/j.leaqua.2011.07.014

33. Shipton, H.; West, M. A.; Dawson, J.; Birdi, K.; Patterson, M. HRM as a predictor of innovation. Hum. Reso. Manag. J. 2006, 16, 3- 14. https://doi.org/10.1111/j.1748-8583.2006.00002.x

34. Sirilli, G.; Evangelista, R. Technological Innovation in Services and Manufacturing: Results from Italian Surveys. Research Policy 1998, 27(8), 881-99. https://doi.org/10.1016/S0048-7333(98)00084-5

35. Spivey, W. A.; Munson, J. M.; Wolcott, J. H. Improving the New Product Development Process. J. Product Innov. Manag. 1997, 14(3), 203-18. http://dx.doi.org/10.1111/1540-5885.1430203

36. Tang, H. K. An Inventory of Organisational Innovativeness. Technovation 1999, 19(1), 41-51. https://doi.org/10.1016/S0166-4972(98)00077-7

37. Woodman, R.W.; Sawyer, J.E.; Griffin, R.W. Toward a theory of organizational creativity. Academy of Manag. Rev. 1993, 18(2), 293-321.

38. Zhuang, L.; Williamson, D.; Carter, M. Innovate or Liquidate - Are All Organizations Convinced': A Twophased Study into the Innovation Process, Manag. Decis. 1999, 37(1), 57-71. https://doi.org/10.1108/00251749910252030 